\title{
Frequency of Lipid Balances and Prevalence of Dyslipidemies in the Biochemistry Laboratory of the Marc Sankale Center of Dakar
}

\author{
Sow Djiby ${ }^{\text {* }}$, A. Ndiaye $^{2}$, Insa Diaw Fall ${ }^{2}$, Sokhna Fall AW ${ }^{2}$, Diédhiou Demba ${ }^{1}$, \\ Ndour Michel Assane ${ }^{1}$, Diallo Ibrahima Mané1, Sarr Anna ${ }^{1}$, Diop Saïd Norou ${ }^{1}$, \\ Ndour-Mbaye Maimouna ${ }^{1}$ and Niama Diop Sall ${ }^{2,3}$
}
${ }^{1}$ Marc Sankale center, Abass NDAO Hospital in Dakar, internal medicine service (Senegal)
${ }^{2}$ Laboratory analyzes Medical Biology, Abass NDAO hospital in Dakar (Senegal)
${ }^{3}$ Faculty of Medicine, Pharmacy and Dentistry (FMPOS) in Dakar, Medical Biochemistry
Laboratory, Senegal

*Corresponding author

\section{A B S T R A C T}

Diabetes mellitus associated with dyslipidemia raises the risk of complications that contribute significantly to cardiovascular morbidity and mortality. The objective was to describe the frequency and prevalence of dyslipidemia in diabetics to better plan follow-

\section{Keywords}

Diabetes, dyslipidemia, prevalence, Senegal

Article Info

Accepted:

24 October 2018

Available Online:

10 December 2018 up. This was a cross-sectional, descriptive study conducted from January 1st, 2016 to December 31st, 2016 at the Marc Sankale diabetes biochemistry laboratory in Dakar. The data collected in the registry were epidemiological, study of diabetes mellitus and cardiovascular risk factors. Included in the study were all patients with at least one lipid status parameter whose results were recorded in the biochemistry laboratory register. In our study population $19.52 \%$ of patients had at least one lipid parameter in their biochemical record. The prevalence of dyslipidemia in our study population was $59.5 \%$. The prevalence of hypercholesterolemia, low HDL cholesterol, high LDL cholesterol, hypertriglyceridemia and mixed hyperlipidemia were respectively: 52.92\%; 5.63\%; $43.56 \% ; 2.48 \% ; 2.04 \%$. The average age of the patients was 55.83 years. The subjects aged 40 to 59 seemed to be more exposed and there was a female predominance. Diabetes is unbalanced at $52.08 \%$. Our work reports a high prevalence of dyslipidemia in diabetics. However, it requires strengthening prevention strategies through appropriate therapeutic education and optimal balance of diabetes mellitus.

\section{Introduction}

Diabetes is a public health problem and according to the 2017 estimates of the (International Diabetes Federation, 2017), the number of diabetics in the world is 425 million. Diabetes mellitus is a risk factor for cardiovascular disease and the 13th leading cause of death in the world (World Health Organization, 2015). It is associated with a high incidence of dyslipidemia constituting a factor aggravating atheromatous risk in this population (Fasanmade et al., 2013; Mithal et $a l ., 2014)$. The goal of cardiovascular disease 
prevention is to reduce the risk associated with each of these factors. The lipid balance is thus one of the elements of the first step of the cardiovascular disease prevention strategy. The aim of this study was to evaluate the frequency of lipid balances and the prevalence of dyslipidemia in patients received at the biochemistry laboratory of the Marc Sankale Diabetic Center in Dakar.

\section{Materials and Methods}

This was a descriptive cross-sectional study carried out at the Dakar Diabetes Center Marc Sankale from January to December 2016. It concerned diabetic patients of all types whose results were included in the laboratory register and were included in the study that is the number of lipid parameters required. Nonincluded diabetic subjects not included in the center register.

For this survey, we selected the following variables:

Sociodemographic characteristics: sex, age grouped by slice

The biochemical parameters identified were: fasting glucose; glycated hemoglobin; lipid status parameters such as total cholesterol, HDL-cholesterol, LDL cholesterol and triglycerides, uricemia, creatinine.

\section{Judgment criteria}

The dyslipidemias were defined in this study according to the criteria of NCEP (The National Cholesterol Education Program) (Expert Panel on Detection, Evaluation, and Treatment of High Blood Cholesterol in Adults, 2001):

Pure hypercholesterolemia: total cholesterol greater than $2 \mathrm{~g} / \mathrm{L}$ and triglycerides less than $<1.5 \mathrm{~g} / \mathrm{L}$.
Low HDL cholesterol levels: HDL less than $0.4 \mathrm{~g} / \mathrm{L}$.

Mixed hyperlipidemia: total cholesterol greater than $2 \mathrm{~g} / 1$ and triglycerides higher than $1.5 \mathrm{~g} / 1$.

Hypertriglyceridemia: total cholesterol lower than $(2 \mathrm{~g} / 1)$ and triglycerides greater than 1.5 $\mathrm{g} / 1$.

High LDL cholesterol: LDL cholesterol> $1.3 \mathrm{~g}$ / 1

The data has been verified, evaluated and validated, and entered using the Google Docs and Microsoft Excel software.

\section{Results and Discussion}

\section{Sociodemographic characteristics}

We included 3503 diabetic subjects during the study period. In our 684-study population19, $52 \%$ of patients had at least one lipid parameter in their biochemical record. Table 1 shows the socio-demographic characteristics of the population at inclusion. The distribution of patients according to the number of lipid parameters per balance sheet (Table 2) revealed that $93.12 \%$ of prescriptions had four parameters, namely total cholesterol, triglycerides, LDL and HDL cholesterol. The prescription frequencies of lipid parameters show a demand for total cholesterol alone in $(4.09 \%)$ by the prescribers.

No lipid assessment request included the three parameters of total cholesterol, triglycerides and HDL cholesterol. The prevalence of dyslipidemia observed in our sample was $51.75 \%$. Hypercholesterolemia (52.92\%), increased LDL (43.56\%) and decreased HDLcholesterol $(5.63 \%)$ were the most common hypertriglyceridemia and mixed dyslipidemia respectively $2.48 \%$ and $2.04 \%$ (Table 3 ). 
Table.1 Epidemiological and clinical profile of patients at baseline

\begin{tabular}{|l|c|}
\hline \multicolumn{2}{|c|}{ Epidemiological and clinical characteristics } \\
\hline Number of cases & 3503 \\
\hline Lipid balance & $684(19,52 \%)$ \\
\hline Women & $2551(72,86) \%$ \\
\hline Sex ratio (M/W) & 0,37 \\
\hline Average age & $55,23 \mathrm{ans}$ \\
\hline Patients <25 years old & $3,81 \%$ \\
\hline Patients >45 years old & $73,07 \%$ \\
\hline Average balance of glycemia & 1,59 \\
\hline Glucose $\mathbf{2}$ g/l & $21,60 \%$ \\
\hline Average glycated hemoglobin & $8,17 \%$ \\
\hline Glycated Hemoglobin> 7\% & $53,55 \%$ \\
\hline Creatinine>13 mg/l & $8,99 \%$ \\
\hline
\end{tabular}

Table.2 The distribution of patients according to the number of lipid parameters by balance sheet

\begin{tabular}{|l|l|c|c|}
\hline Number of parameters & \multicolumn{1}{|c|}{ Lipid balance } & Number & Percentage \\
\hline 1 parameter & CT & 28 & $4,09 \%$ \\
& TG & 0 & $0 \%$ \\
\hline 2 parameters & CT,TG & 7 & $0,29 \%$ \\
& CT, HDL & 2 & $1,16 \%$ \\
& TG, HDL & 0 & $0 \%$ \\
\hline 3 parameters & CT,HDL,LDL & 8 & $1,16 \%$ \\
& HDL,LDL,TG & 2 & $0,29 \%$ \\
\hline \multirow{4}{*}{ parameters } & CT, HDL, LDL, TG & 637 & $93,12 \%$ \\
\hline Total & & 684 & $100 \%$ \\
\hline
\end{tabular}

$\mathrm{CT}=$ Total Cholesterol

$\mathrm{TG}=$ Triglycerides

$\mathrm{LDL}=\mathrm{LDL}$ cholesterol

HDL $=$ HDL cholesterol

Table.3 Patient dyslipidemia profile

\begin{tabular}{|l|c|}
\multicolumn{2}{|c|}{ Characteristics of dyslipidemia } \\
\hline \multicolumn{1}{|c|}{ Profile } & Number (Percentage) \\
\hline Isolated hypercholesterolemia & $362(52,92 \%)$ \\
\hline Hypertriglyceridemia & $17(2,48 \%)$ \\
\hline Isolated Low HDL cholesterol & $36(5,63 \%)$ \\
\hline High LDL cholesterol & $298(43,56 \%)$ \\
\hline Mixed dyslipidemia & $14(2,04 \%)$ \\
\hline
\end{tabular}


Table.4 Epidemiological and clinical profile of patients according to dyslipidemia

\begin{tabular}{|l|c|c|}
\hline \multicolumn{3}{|c|}{ Epidemiological and clinical characteristics according to dyslipidemia } \\
\hline Number of cases & Dyslipidemia YES & Dyslipidemia NO \\
\hline women & 407 & 277 \\
\hline Sex ratio (M/W) & $316(77,45 \%)$ & $248(74,92 \%)$ \\
\hline Average age & 0,28 & 0,33 \\
\hline Patients < 40 years old & 55,83 years & 53,04 years \\
\hline Patients of age (40-59) years & $28(6,87 \%)$ & $46(13,89 \%)$ \\
\hline Patients >60 years old & $227(55,77 \%)$ & $183(55,28 \%)$ \\
\hline Average balance of glycemia & $152(37,34 \%)$ & $101(30,51 \%)$ \\
\hline Glucose > 2g/d & 1,6 & 1,56 \\
\hline Average glycated hemoglobin & $100(24,57 \%)$ & $66(20,56 \%)$ \\
\hline Glycated Hemoglobin> 7\% & $8,34 \%$ & $7,94 \%$ \\
\hline Creatinine>13 mg/l & $212(52,08 \%)$ & $163(53,26 \%)$ \\
\hline
\end{tabular}

Table.5 Distribution of dyslipidemia by sex

\begin{tabular}{|l|c|c|c|}
\hline \multicolumn{4}{|c|}{ Characteristics of patients } \\
\hline & MEN & WOMEN & Total \\
\hline Number of cases & 91 & 316 & 407 \\
\hline Average age & 55,32 years & 55,98 years & 55,23 \\
\hline Average balance of glycemia & 1,70 & 1,65 & 1,59 \\
\hline Average glycated hemoglobin & $8,51 \%$ & $8,29 \%$ & $8,17 \%$ \\
\hline Hypercholesterolemia & $76(46,06 \%)$ & $286(55,31 \%)$ & 362 \\
\hline Hypertriglyceridemia & $6(3,82 \%)$ & $11(224 \%)$ & 17 \\
\hline Low HDL cholesterol & $18(11,84 \%)$ & $18(3,62 \%)$ & 36 \\
\hline High LDL cholesterol & $70(45,75 \%)$ & $228(46,15 \%)$ & 298 \\
\hline Mixed dyslipidemia & $6(5 \%)$ & $8(1,41 \%)$ & 14 \\
\hline
\end{tabular}

Table.6 Distribution of dyslipidemia according to age

\begin{tabular}{|l|c|c|c|c|}
\hline \multirow{2}{*}{ Parameters } & \multicolumn{4}{|c|}{ Age } \\
\hline Hypercholesterolemia & $<40$ years & $(40-59$ years $)$ & $>60$ years & Total \\
\hline Hypertriglyceridemia & 18 & 200 & 134 & 362 \\
\hline Low HDL cholesterol & 2 & 11 & 4 & 17 \\
\hline High LDL cholesterol & 4 & 14 & 18 & 36 \\
\hline Mixed dyslipidemia & 19 & 161 & 108 & 288 \\
\hline
\end{tabular}

Women accounted for $77.45 \%$ with a sex ratio $\mathrm{M} / \mathrm{W}$ was 0.28 . The average age of patients was 55.83 years with extremes ranging from 4 to 87 years. Patients aged (40- 
59) accounted for $55.77 \%$ of cases. Patients over 60 accounted for 37.34\%. Glycemic equilibrium was not reached in $52.08 \%$. Renal failure is noted in 20 patients (Table 4). The distribution of dyslipidemia as a function of age and sex (Table 5 and 6) shows that subjects aged 40 to 59 and women are more exposed.

The lipid profile is necessary for the detection of dyslipidemia. This study, whose objective was to determine the frequency of lipid balances and the prevalence of dyslipidemia, showed over a period of one year that 684 patients out of the 3503 requests for biochemical assessments received at the biochemistry laboratory, had made the subject of a lipid assessment, i.e. a frequency of $19.52 \%$. A similar study conducted in Cocody by (Tahiou et al., 2010) found a frequency of lipid budgets of $5.7 \%$. This low frequency of prescriptions of the biological balance in general could be explained by the will of the prescribers to minimize the costs of these assessments. According to (Manlan, 2001) the prescription of lipid examinations would be done by specialists in cardiovascular diseases.

In our study $93.12 \%$ of the requests included the four parameters and $4.09 \%$ demand for cholesterol alone. For (Tahiou et al., 2010) in their study observed that requests for biological tests included on average three biological tests.

The prevalence of dyslipidemia observed in our study is very high $(51,75 \%)$, which is like that found in Côte d'Ivoire by (Lokrou et al., 1998) in diabetic subjects (47.4\%). These figures are like those found by (Dominique Doupa et al., 2014) in a study in St Louis $(63.8 \%)$. Our results far exceed those found by Cisse $\mathrm{F}$ in Senegal (Fatou Cisse et al., 1937) in Algeria (14.3\%) (Yahia-Berrouiguet, 2009) and Mauritania (> 14.8\%) (MS / WHO, 2006). Our prevalence is consistent with those observed in the industrialized countries that exceed 30\% (Tóth et al., 2012). Dyslipidemia plays a key role in the genesis of cardiovascular diseases and increases mortality morbidity. Screening is important for reducing cardiovascular mortality.

Pure hypercholesterolemia is the most common dyslipidemia observed in our study. For Ndour Mbaye in his study in St Louis (Mbaye et al., 2011) it was a high prevalence of high LDL cholesterol, while that of hypertriglyceridemia is low. It differs in this respect from the study by (Lokrou, 1998), who described $44 \%$ hypercholesterolemia and $17 \%$ hypertriglyceridemia, as well as the Framingham study (Boland et al., 2000), which showed a predominance of hypertriglyceridemia in the diabetic population. So, the clear majority of our subjects who had hypercholesterolemia also had high LDL cholesterol. The low prevalence of mixed hyperlipidemia and pure hypertriglyceridemia probably results from lipid-lowering therapy given by prescribers. For this purpose, it is necessary for prescribers to complete the clinical indications to allow biologists to interpret the results. About age, our study showed that subjects from 40 to 59 were the most. For Cisse F, the most affected age group is 39 to 59 years old (Fatou Cisse et al., 1937). Women seem to be more exposed to hypercholesterolemia. Indeed, most studies have found a predominance of dyslipidemias and more particularly hypercholesterolemia in women (Dominique Doupa et al., 2014; Scheidt-Nave et al., 2012; Pessinaba et al., 2013). In the National Health Nutrition Study conducted in 2006-2007, the prevalence of dyslipidemias is about $67 \%$ in men (Ferrieres et al., 2005).

The determination of the lipid balance is fundamental in diabetics to watch for possible cardiovascular complications. Unfortunately, 
this assessment is under-requested by practitioners according to this study, hence the recommendation to systematize it in all diabetic monitoring reports. Our work reports a high prevalence of dyslipidemia in diabetics. However, it requires strengthening prevention strategies through appropriate therapeutic education and optimal balance of diabetes mellitus.

\section{References}

Boland B, Chenu P, Descamps O, et al., Dyslipidemia in general medicine: detection, attitude and treatment. Leuven Méd 2000; 119: 79-90.

Dominique Doupa, Abdou Salam Mbengue, Fatou Agne Diallo, Modou Jobe, Arame Ndiaye, Adama Kane, Alassane Diatta, Meissa Toure. Lipid profile frequency and the prevalence of dyslipidemia from biochemical tests at St. Louis University Hospital in Senegal. Pan African Medical Journal. 2014, 17:75

Expert Panel on Detection, Evaluation, and Treatment of High Blood Cholesterol in Adults. Executive Summary of the Third Report of the National Cholesterol Education Program (NCEP) Expert panel on detection, assessment, and treatment of high blood cholesterol in adults (Adult Treatment Panel III). JAMA. 2001; 285 (19): 2486-97.

Fasanmade, OA, Odeniyi IA, Amira CO, et al., Association of body mass index and abdominal adiposity with atherogenic lipid profile in Nigerians with type 2 diabetes and / or hypertension. Niger Med J 2013; 54 (6): 402-7.

Fatou Cisse, Diallo Agne Fatou, Alassane Diatta: Prevalence of dyslipidemias at the biochemistry laboratory of Aristide Dantec University Hospital in Dakar, Senegal, Pan African Medical Journal ISSN: 1937-8688 (www.panafricanmed-journal.com)
Ferrieres J, Ruidavets JB, Perret B, Dallongeville J, Arveiler D, Bingham A, Amouyel P, Haas B, Ducimetiere P. Prevalence of dyslipidemias in a representative sample of the French population. Heart and Vessel Archives. 2005, 98 (2): 127-32.

International Diabetes Federation. IDF Diabetes Atlas, 8th edn. Brussels, Belgium: International Diabetes Federation, 2017.

Lokrou A. (1998) Hyperlipidemia and diabetes in Côte d'Ivoire: cross-sectional study of 132 cases. Medicine of Black Africa; 45 (10): 555-557

M.-N. Mbaye, K. Niang, A. Sarr, A. Mbaye: Epidemiological Aspects of Diabetes in Senegal: Results of a Survey of Cardiovascular Risk Factors in the City of Saint-Louis. Metabolic Disease Medicine - December 2011 - Vol. 5 No 6

Manlan K (2001) Activity report of the biochemistry laboratory of the University Hospital of Treichville for 06 months. Thesis Med, $\mathrm{n}^{\circ} 2980$.

Mithal, A, Majhi D, Shunmugavelu M, et al., Prevalence of dyslipidemia in adult Indian diabetic patients: A cross sectional study (SOLID). Indian J Endocrinol Metab 2014; 18 (5): 642-7.

MS / WHO. Report of the survey on noncommunicable diseases according to the WHO STEP wise approach: study of arterial hypertension, diabetes and other risk factors in Nouakchott Mauritania. 2006. Google Scholar

Pessinaba S, Mbaye A, Yabeta GAD, Harouna $\mathrm{H}$ and et al., Prevalence survey of cardiovascular risk factors in general population in Saint-Louis (Senegal). Ann Cardiol Angeiol. 2013; 62 (4): 253-258.

Scheidt-Nave C, Du Y, Knopf H, Schienkiewitz A, Ziese T, Nowossadeck E, Gößwald A, Busch MA. Prevalence 
of dyslipidemia among adults in Germany: Results of the German Health Interview and Examination Survey for Adults (DEGS 1). BGG. 2012; 56 (5 6): 32530 .

Tiahou G, Deret K, World A. Agniwo Camara-Cisse M, Djohan Y, Djessou P, SESS D. Frequency of lipid balances and prevalence of dyslipidemias in the biochemistry laboratory of the Cocody chu. J Sci Pharm Biol. 2010; 11 (2): 605.

Tóth PP, Potter D, Ming EE. Prevalence of Lipid Abnormalities in the United States: The National Health and
Nutrition Examination Survey. J Clin Lipidol. 2012; 6 (4): 325-30.

World Health Organization. The global burden of disease: 2015; Available at: http://www.who.int/healthinfo/global_b urden_disease/2015_report_update/en/i ndex.html

Yahia-Berrouiguet A, Benyoucef $\mathrm{M}$, Meguenni K, Faivre B, Brouri M. Survey on the prevalence of risk factors for cardiovascular diseases in Tlemcen (Algeria). Diabetes Metab. 2009; 35 (1): 42-3.

\section{How to cite this article:}

Sow Djiby, A. Ndiaye, Insa Diaw Fall, Sokhna Fall AW, Diédhiou Demba, Ndour Michel Assane, Diallo Ibrahima Mané, Sarr Anna, Diop Saïd Norou, Ndour-Mbaye Maimouna and Niama Diop Sall. 2018. Frequency of Lipid Balances and Prevalence of Dyslipidemies in the Biochemistry Laboratory of the Marc Sankale Center of Dakar. Int.J.Curr.Microbiol.App.Sci. 7(12): 3276-3282. doi: https://doi.org/10.20546/ijcmas.2018.712.379 